\title{
O estranho e sofisticado Alexei Bueno
}

\section{Mires Batista Bender*}

\begin{abstract}
Resumo: O poeta Alexei Bueno faz parte do seleto grupo de autores que escrevem poesia metafísica no Brasil hoje. Atendendo ao que Thomas Eliot classificou como "Uma robusta racionalidade sob a leve graça lírica", Bueno desenvolve uma lírica com alto grau de sensibilidade e delicadeza, no entanto, sua poética mantém uma profunda carga de racionalização sobre a experiência humana, tendo sido definida como "poesia do pensamento". Habitados pelos mitos grecolatinos, seus deuses e heróis, seus poemas apresentam um paralelo entre o ideal olímpico arcaico e a presença diária da reificação nas sociedades modernas. Este ensaio estuda o aproveitamento que Bueno faz dos cenários e personagens das civilizações clássicas para, através deles, apresentar sua reflexão sobre a modernidade.
\end{abstract}

\begin{abstract}
The Brazilian poet, Alexei Bueno, belongs to the select group of writers who write metaphysical poetry in the country, nowadays. Attending to what Thomas Eliot classifies as "a tough reasonableness beneath the slight lyric grace”, Bueno's poetry develops a very high level of sense and tenderness, nevertheless, it preserves an intense potential of rationalization about human experience, being reputed as "the poetry of thought". His poems are crowded of Greek and Latin myths and evince the parallel between the ancient Olympic model and the oppressive presence of materiality in the modern societies. This essay works on Bueno's utilization of sceneries and characters from classic civilizations, to show the way he proposes his ideas about modernity.
\end{abstract}

Keywords: poetry; myth; metaphysics.

Alexei Bueno nasceu no Rio de Janeiro, em 26 de abril de 1963. Publicou mais de dez livros em vinte anos de produção e é um dos mais cultuados e premiados poetas da nova geração no Brasil. É também um respeitado estudioso de literatura brasileira. Além dos livros de poesia, possui vários textos críticos, antologias, organização de obras completas e tradução de poemas. Em janeiro de 2002, Bueno provocou rebuliço na poesia brasileira, com sua "Carta Aberta aos Poetas Brasileiros" criticando a presença de uma suposta ditadura estética, que rejeita o poema longo e os temas profundos.

Em entrevista a Eliane Azevedo para a Revista Agulha, o poeta declara que há na poesia que se faz nos dias de hoje no Brasil, uma corrente que considera "poeticamente incorreto" ser sério e encarar a realidade. Esta tendência nega qualquer visão direta do lado trágico da vida e rejeita temas como a morte, a miséria e o sofrimento. Ao contrário dessa onda, navega sua poesia, que tem, segundo ele mesmo, "ligações com o Simbolismo

\footnotetext{
* Mires Batista Bender é mestranda do Curso de Literaturas Brasileira, Portuguesa e Luso-Africanas da Universidade Federal do Rio Grande do Sul.
} 
português e com a poesia grega". Sua poesia apresenta complexidade conceitual, exploração dos recursos imagéticos e da metáfora elaborada enquanto faz a reflexão sobre as questões que substanciam a experiência humana, dentro da mais profunda veia da poesia metafísica.

No ensaio intitulado "Os Poetas metafísicos" que publica em 1921, em homenagem ao poeta inglês John Dryden, Thomas Eliot (1989, p. 113) diz que a expressão "poesia metafísica" havia sido relegada por rotular "um estranho e sofisticado gosto". Por declarar este gosto estranho e sofisticado pelos temas metafísicos, o poeta Alexei Bueno recebe, neste ensaio, os adjetivos que dão título ao trabalho.

Na sua introdução à antologia Poesia metafísica, em que comenta o ensaio de Eliot, Aíla Gomes (1989, p. 11-33) aponta as principais características que marcam as obras de grandes representantes desta tendência. Tais marcas podem ser assinaladas na obra de Bueno, que traduz a perfeita "unificação de pensamento e sensibilidade", conforme reconhece a crítica brasileira. Para Pedro Lyra, Bueno faz "a poesia de pensamento" (jornal $O$ Globo, 24/1/2004), e Jameson Buarque registra que o nosso poeta "tem as veias nutridas de imaginário, razão e sentimento" (Jornal de Poesia, s/d). Segundo Aíla, "uma outra especificidade do gênio poético dos metafísicos reside na apresentação usual do sensuous thought em uma aura de wit" (GOMES, 1989, p. 13). De difícil definição, este conceito vai encontrar maior clareza na afirmação de Eliot (1989, p. 129), em ensaio dedicado a Andrew Marvell, naquele mesmo livro, "uma flexível racionalidade sob o frágil encanto lírico”. Seus poemas com forte pendor espiritual, em que o humano é indissoluvelmente ligado ao divino, também marcam a inspiração metafísica, como na "Ode X" do livro A Via estreita (BUENO, 1995, p. 56):

Caminhas aqui na noite, mas estás lá, no grande quadrilátero de Quéops,

Esperando a aurora, que é em ti que nasce no mundo,

Enquanto o cosmos explode e retrai-se em matéria, amealhando o espírito Que somos - nós - no pulsar do coração divino!

O poeta usa material profano em poemas lírico-religiosos, "Pã pelos becos carrega a cruz" (BUENO, 1998, p. 223), e o tema religioso é sempre atravessado pela inquirição metafísica, como no poema “Os viajantes” (BUENO,1955, p. 224):

Quem sabe? Há já muito nos fomos,

Largamos a calma manhã...

Aonde Deus daria os seus pomos?

Clamaram os loucos que somos,

Mas a fala é a arte mais vã.

Ainda, conforme Aíla Gomes (1989, p. 15), "muitas vezes, entrelaçado ao tema do amor, surge o da morte", de que é exemplo o poema "Espólio" (BUENO, 1998, p. 341):

No fim de tudo, quando os adorados 


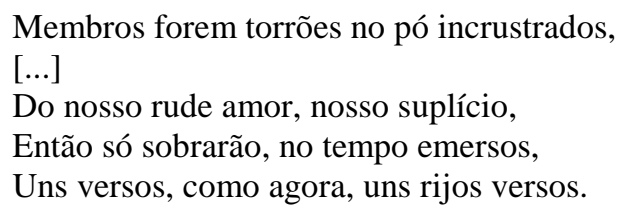

Bueno também faz uso do conceit, recurso muito usado pelos poetas metafísicos e que aparece como uma explicação inusitada para algo que se apresenta difícil de explicar, como em: "E enquanto os segundos se cruzam urdindo seu manto/ [...] a Dor majestosa [...]/ Vai ficando pálida, vai ficando tênue/ Como as ferventes cartas de amor e de morte de amor nas gavetas", onde o poeta usa a imagem de cartas que falam de amor e morte em conteúdo "fervente", abandonadas ao esquecimento numa gaveta, para explicar a dor, a princípio "magestosa", que vai, com o passar do tempo, perdendo intensidade. (BUENO, 1995, p. 53).

A apreciação inquieta sobre o material e o espiritual, a morte e o transcendente e as demais questões ligadas à condição humana aparecem na poesia de Bueno na maioria das vezes, traduzidas pelo discurso mítico. Clássicas personagens lendárias, deuses e heróis frequientam sua obra que visita os homens e seu tempo, tanto nas cidades da civilização helênica como nas avenidas das grandes metrópoles modernas. Representante da permanência dos mitos na poesia moderna brasileira (como o Paulo Leminski, do Metaformose ou o Marcus Accioly, do Sísifo), Bueno parece acompanhar uma maneira de fazer poesia que é inaugurada com o poeta Mário Faustino no final dos anos 1950. Marcada por uma profunda inquietação espiritual, pela apurada estrutura da linguagem, o uso de imagens e metáforas inesperadas, pela apresentação do poema longo - tão rejeitado pela moda concretista daquele momento - e sobretudo pela forte presença dos mitos, a poesia de Faustino marca o início de uma nova geração literária no Brasil ${ }^{1}$. Assim como Faustino, Bueno é considerado um bardo moderno. Seus poemas são de longo fôlego, sem economia de versos nem de imagens, seus temas são densos, as conexões nunca são óbvias, e não há preocupação com o "conforto" do leitor. Segundo Hugo Friedrich (1978, p. 16), essa “obscuridade intencional" é uma característica da lírica moderna. Ele diz que a poesia em geral não busca o inequívoco e que a lírica moderna reconhece aquela "glória de não ser compreendida", de que falou Baudelaire. Ela coloca em tensão forças que agem em estratos pré-racionais e põe em contraste traços de origem "arcaica, mística e oculta". A poesia de Alexei Bueno fala desta origem arcaica, dos mitos presentes na formação da nossa civilização enquanto vai tecendo os vínculos entre o visível e o invisível, conforme salientou Henri Peyre (1983, p. 14), falando da simbólica.

\footnotetext{
${ }^{1}$ O poeta e crítico cearense Pedro Lyra diz que Faustino é, na poesia brasileira, o precursor da Geração 60, pois sua obra de estréia, única publicada em vida, antecipa certas temáticas e ideais estéticos dessa geração. (LYRA, 1995, p. 91-92).
} 
Em La Quête métaphysique dans la poésie moderne, Mihae Son (1995, p. 6-8) nos ensina que o engajamento da poesia moderna é na questão metafísica que busca o infinito no transitório. Ressalta também que a poesia metafísica apresenta as grandes indagações da alma humana sem, no entanto, procurar seu equacionamento. Ao poeta metafísico importa a busca, não a resposta, ele é o porta-voz de um coletivo e carrega de tensão os questionamentos sobre a existência. De acordo com Mikel Dufrenne, em seu estudo sobre $O$ poético (1969, p. 188), a grande interrogação metafísica é perguntar pelo fundo das coisas, não pelo fundamento de tudo, mas pelo seu fundo, o que ultrapassa a questão da relação do homem com o mundo para questionar sobre a origem ou a causa desta correlação para, assim, buscar o primordial, pois é através da busca do primordial, de uma volta ao início das coisas, que fazemos contato com o transcendente. E perguntar sobre origem das coisas está na essência do mito, o que o mantém como recurso para os questionamentos de vários poetas modernos.

A poesia sempre teve profundas ligações com o mito. Conforme Cassirer (1977, p. 244 ), isto se prova desde a sua origem, porque mito e poesia surgem num tempo primordial, da ausência da linguagem racional, em que só a linguagem simbólica existia. É também, através da linguagem poética, que o homem mantém contato com seu eu mais profundo. Em O arco e a lira, Otávio Paz (1982, p. 189) diz que a poesia revela a condição do homem, ela é "o ato pelo qual o homem se funda e se revela a si mesmo". No ensaio intitulado "Poesia e mito”, Ana Maria Lisboa de Mello (2003, p. 11-26) apresenta uma abrangente análise dos trabalhos destes e de diversos outros autores sobre poesia mítica, desenvolvendo um estudo sobre a presença dos mitos na poesia do século XX através da apreciação de poemas de Cecília Meireles, Leminski e de Alexei Bueno, entre outros. No seu texto, revela-se a força com que o mito marca presença na poesia de inspiração metafísica e das possibilidades ilimitadas que esta abordagem oferece à indagação da universalidade dos problemas e comportamentos humanos.

Por meio da sondagem metafísica e das idéias eternas, captadas do gênio das civilizações clássicas, Alexei Bueno faz o questionamento da modernidade e propõe a poesia como instância da reflexão sobre a vida e o ser. Através de grande variedade de formas e metros seus poemas nos põem em contato com o espírito olímpico grego e as aventuras de seus heróis como um parâmetro para pensar o homem moderno:

Se nos fosse dado ser isso,

Um Alexandre cada um, varrendo a Terra,

Plena nos seria a vida. Mas a bonança é a nossa inimiga,

A calmaria, não a tempestade, é que nos espera ao varar o oceano,

Nos desfiladeiros minúsculos, com o único perigo do nada,

é que nós marcharemos, 
Ainda que borbulhe em nós o canto do deus, e Amor Vencedor, Durante ou após nosso olhar, pisoteie a disputa dos vermes.

(Fragmento de "Ode IX", do livro A Via Estreita , 1998, p. 50).

O poeta faz uma imersão na atmosfera da Hélade, cidade centro da cultura helênica, para apresentar a poesia falando do que há de mais profundo no homem: sua fé e sua interrogação a respeito dos mistérios da alma. Do livro Poemas Gregos (1998, p. 265), temos:

\footnotetext{
Eu, Polimestor, o sofista, órfão de Deus,

Tendo perdido toda a crença, hoje declaro

Pelas acrópoles da Iônia, e pela Hélade,

A quantos me ouçam, que mais vale que a verdade

O que eu perdi. Seja o que for ela, a verdade.
}

A fé que o eu lírico perdeu, na humanidade, é mais importante do que qualquer caminho que a verdade possa revelar. Ernest Becker, no seu livro A negação da morte (s/d, p. 218-221), explica que, até o séc. XIX, todas as questões interiores do homem eram pertencentes ao campo da alma, do místico, e eram tratadas pela religião. Vieram, então, as ciências para ensinar que tudo estava sujeito às leis da causalidade - não havia mais a alma, só o eu. As questões ligadas ao interior do homem, agora eram fruto das relações sociais e não da intervenção divina. Tudo estava explicado: o riso, as lágrimas, a linguagem humana, a arte... Mas a teoria da evolução não explicara qual a força interior que conduzia um ente ao "animal capaz de autoconsciência, que é o que ainda entendemos como 'alma"”. Os questionamentos, que advieram deste conhecimento, revelaram ao homem a fragilidade de sua fé. Explorando a paisagem helênica, o poema de Bueno nos apresenta a precariedade do homem moderno, sozinho com seus problemas, e sem saber onde situar todas as suas mais antigas convicções. De que lhe adianta saber a "verdade", se o mais importante se perdeu?

Em "Helena", poema do livro Lucernário (1998, p. 327-328), está o senso da fugacidade do tempo e da efemeridade do homem:
No cômodo onde Menelau vivera
Bateram. Nada. Helena estava morta.
A última aia a entrar fechou a porta,
Levaram linho, ungüiento, âmbar e cera.

Aqui aparece a simplicidade das palavras contrastando com a complexidade do tema, que Hugo Friedrich (1978, p. 16) viu na lírica moderna:

\footnotetext{
Noventa e sete anos. Suas pernas

Eram dois secos galhos recurvados.

Seus seios até o umbigo desdobrados

Cobriam-lhe três hérnias bem externas.
}

Bueno encontrou no mundo mítico a sua expressão para traduzir o que há de substancial na experiência humana universal, de forma intensa e perturbadora: 
Na boca sem um dente os lábios frouxos

Murchavam, ralo pêlo lhe cobria

O sexo que de perto parecia

Um pergaminho antigo de tons roxos.

Maquiaram-lhe as pálpebras vincadas,

Compuseram seus ossos quebradiços,

Deram-lhe à boca uns rubores postiços,

Envolveram-na em faixas perfumadas.

Então chamas onívoras tragaram

A carne que cindiu tantas vontades.

Quando sua sombra idosa entrou no Hades

As sombras dos heróis todas choraram.

A grandiosa Helena, símbolo de beleza e sedução, que "cindiu tantas vontades”, está reduzida a uma figura grotesca. O poeta apresenta a redução dos valores terrenos ao que eles realmente são: perecíveis, precários. Todos eles são da conta do que o homem moderno julga mais sólido: o poder, a beleza exterior. Porém, como disse Marshall Berman (1992, p. 15), aproveitando a frase de Marx: "tudo que é sólido desmancha no ar", somente o verdadeiro valor de Helena fará com que chorem todos heróis, quando sua sombra idosa entrar em Hades.

A abordagem que Bueno faz da morte é repleta de questionamentos e inquietações. Diferente da visão de Mário Faustino ou de Cecília Meireles - que Ana Mello apresenta no ensaio anteriormente citado "Poesia e mito" - em que a morte é vista como o encerramento natural de um ciclo, numa aceitação total do destino humano. A visão de Bueno traz a questão da fragilidade do homem, da consciência de mortalidade humana, que ele apresenta lado a lado com a imortalidade dos deuses.

Assim como fez o poeta Mário Faustino, Bueno 'reinventa' os mitos. Traz o mito grego para os tempos modernos e lhe atribui novos sentidos. Neste poema de 1985, apresenta o mito de Prometeu (condenado por roubar o fogo para favorecer os humanos, a ter o fígado eternamente devorado por um abutre) para tratar da angústia do homem moderno, da sua prisão aos valores terrenos, do sentimento de vazio e de reificação:

Desde que o fogo, Prometeu, nos deste,

No Cáucaso do nosso próprio espírito

Como tu, mesmo em marcha, estamos presos

E o tempo é o nosso abutre.

Para Alexei Bueno, "o tempo" é o abutre que bica diariamente o fígado do homem moderno, porque na sua corrida para buscar o progresso e para ser bem sucedido em tudo, ele se mantém aprisionado ao seu destino, "agrilhoado":

Nunca mais, por tua causa, pararemos,

Em nosso próprio andar agrilhoados

Como cegos que gemem por não verem

O que vêem no entanto. 


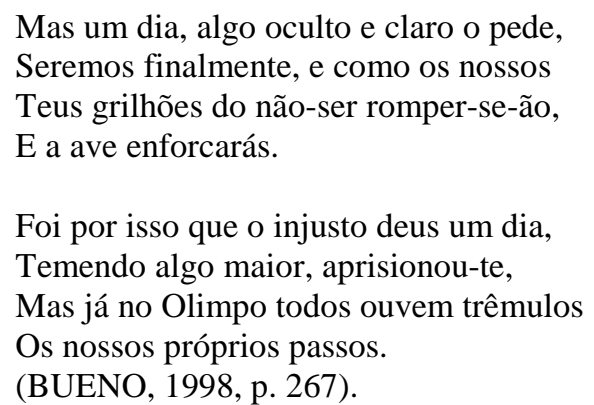

No Dicionário de mitos literários, Pierre Brunel (1988, p. 784-793) diz que, no século XX, Prometeu representa toda a revolta de ordem metafísica e religiosa. A expressão "homem prometéico" surge para identificar aquele que tem uma atitude de contestação aos valores tradicionais. Segundo o poema de Bueno, "algo oculto e claro", a própria poesia, está exigindo que o homem prometéico rompa os grilhões "do não-ser" e os use para enforcar o abutre. Só assim estará liberto da rotina do materialismo da vida moderna.

A poesia de Alexei Bueno encontrou no discurso mítico a expressão ideal para fazer a reflexão sobre a aventura dos homens que passeiam pelos pátios das cidades modernas rumo ao terceiro milênio. Ao revisitar os mitos, o poeta atualiza seu valor de símbolo e lhes confere novas significações, as quais irão confirmar a vocação que eles têm para ilustrar os temas da história humana em todos os tempos. A permanência contemporânea dos heróis e divindades arcaicas possibilita o retorno a um tempo anterior ao conflito social, período de perfeita comunhão entre o homem e a natureza, em que poesia, linguagem e mito eram forças integrantes do mesmo ato sagrado. Na poética de Bueno, carregadas dos temas atuais, as figuras míticas passam a equilibrar passado e futuro, matéria e espírito. A harmoniosa integração entre pensamento, linguagem e sentimento, presente na obra de Bueno, sempre permeada por uma visão crítica da modernidade, consagra a missão do poeta como tradutor de seu tempo, mas, principalmente, ilumina uma perspectiva de ampliação e renovação aos caminhos que se abrem ao fazer poético no Brasil nos nossos dias.

\section{Referências}

AZEVEDO, Eliane. 31/1/2002. Poeticamente incorreto. Disponível em: <http://www.revista.agulha.nom.br/disseram40.html> Acesso em: 13. out. 006.

BECKER, Ernest. A Negação da morte. São Paulo: Círculo do Livro, [s/d].

BERMAN, Marshall. Tudo que é sólido desmancha no ar: a aventura da modernidade. São Paulo: Companhia das Letras, 1992. 
BRUNEL, Pierre (org.). Dicionário de mitos literários. Brasília: UNB; Rio de Janeiro: José Olympio, 1988.

BUARQUE, Jameson. [s/d]. A propósito da carta de Alexei Bueno. Disponível em: $<$ http://www.revista.agulha.nom.br/disseram40a.html> Acesso em 10. out. 2006.

BUENO, Alexei. A Via Estreita. Rio de Janeiro: Nova Fronteira, 1995.

BUENO, Alexei. Poemas Reunidos. Rio de Janeiro: Nova Fronteira, 1998.

CASSIRER, Ernest. Antropologia filosófica. São Paulo: Mestre Jou, 1977.

DUFRENNE, Mikel. O poético. Porto Alegre: Globo, 1969.

ELIOT, T. S. Ensaios; tradução, introdução e notas de Ivan Junqueira. São Paulo: Art, 1989.

FRIEDRICH, Hugo. Estrutura da lírica moderna: da metade do século XIX a meados do século XX. São Paulo: Duas Cidades, 1978.

GOMES, Aíla de Oliveira. Introdução. In: Paulo: Companhia das Letras,1991. p. 11-33.

(org.). Poesia metafísica: uma antologia. São

LYRA, Pedro. 24/1/2004. A poesia alegórica e inspircional do oracular e telúrico Alexei Bueno. Disponível em: <http://www.livrariacultura..br/script/cutura/resenhas.html> Acesso em: 10. out. 2006.

LYRA, Pedro. A poesia da Geração 60. Rio de Janeiro: Topbooks, 1995.

MELLO, Ana Maria Lisboa de. Poesia e mito In: SANTOS, Dulce Oliveira Amarante dos; TURCHI, Maria Zaira (Orgs.). Encruzilhadas do imaginário. Goiânia, Cânone, 2003. p. 11-26.

PAZ, Octavio. O arco e a lira, Rio de Janeiro: Nova Fronteira, 1982.

PEYRE, Henri. Símbolo, simbólica e simbolismo. In: A literatura simbolista. SãoPaulo: Cultrix, 1983. p. 11-16.

SON, Mihae. La quête métaphysique dans la poésie moderne: des annés 1920 aux anneés 1960. Toulouse Septentrión Presses Universitaires, 1995. 